\title{
A ALQUIMIA E OS CAMINHOS PERCORRIDOS PARA A INCORPORAÇÃO DA QUÍMICA COMO CIÊNCIA MODERNA
}

\author{
ALCHEMY AND THE PATHS TO INCORPORATING CHEMISTRY AS A MODERN \\ SCIENCE
}

Washington Lombarde ${ }^{1}$, Neide Maria Michellan Kiouranis ${ }^{2}$

Recebido: janeiro/2020 Aprovado: novembro/2020

\begin{abstract}
Resumo: O presente trabalho se dedica a um episódio da História da Química, a Alquimia, à qual não é dada a devida atenção por educadores no meio acadêmico, visto que, muitas vezes, professores e alunos desconhecem os caminhos que levaram à origem da Química. Diante desse contexto, o presente trabalho tem como objetivo apresentar a História da Alquimia desde sua origem em Alexandria, seu desenvolvimento em contextos variados em diversos lugares no mundo até o seu rompimento com os trabalhos de Robert Boyle. A Alquimia trouxe inúmeras contribuições para a incorporação da Química como Ciência Moderna, tais como o desenvolvimento de técnicas e instrumentos, além da descoberta de substâncias utilizadas até os dias atuais. Através da historiografia, buscou recontar brevemente os aspectos históricos do conhecimento alquímico, por meio da utilização de fontes secundárias (trabalhos de autores contemporâneos). Para tanto, foram consideradas duas abordagens historiográficas: a internalista e a externalista, a fim de compreender o contexto no qual esse conhecimento se desenvolveu. Diante da historiografia realizada, percebe-se a escassez de material especializado acerca do assunto, o que, por sua vez, dificulta a elaboração de materiais mais aprofundados. Daí a necessidade de desenvolver pesquisas que abordem a Alquimia atrelada a aspectos históricos e filosóficos da Ciência.
\end{abstract}

Palavras-chave: Alquimia, latroquímica, Robert Boyle, Química Moderna.

Abstract: The present work is dedicated to an episode in the History of Chemistry, Alchemy, which is not given due attention by educators in the academic environment, since teachers and students are often unaware of the paths that led to the origin of Chemistry. Given this context, the present work aims to present the History of Alchemy from its origin in Alexandria, its development in varied contexts in different places in the world until its break with the works of Robert Boyle. Alchemy has brought numerous contributions to the incorporation of Chemistry as Modern Science, such as the development of techniques and instruments, in addition to the discovery of substances used until today. Through historiography, he sought to briefly retell the historical aspects of alchemical knowledge, through the use of secondary sources (works by contemporary authors). For that, two historiographic approaches were considered: the internalist and the externalist, in order to understand the context in which this knowledge developed. In view of the historiography, there is a shortage of specialized material on the subject, which, in turn, makes it difficult to elaborate more in-depth materials. Hence the need to develop research that addresses Alchemy linked to historical and philosophical aspects of Science.

Keywords: Alchemy, latrochemistry, Robert Boyle, Modern chemistry.

1 (D) 0000-0001-7374-6856 - Mestre em Ensino de Ciências pela Universidade Estadual de Maringá (UEM). Professor de Química na Secretaria de Estado da Educação e do Esporte do Paraná. Apucarana, Paraná, Brasil. Avenida Doutor Munhoz da Rocha, 310, Centro, CEP: 86800-607, Apucarana, Paraná. E-mail: washingtonquimico2011@gmail.com

2 (D) 0000-0002-1279-9994 - Doutora em Educação para a Ciência pela Universidade Estadual Paulista (UNESP). Mestre em Ensino de Química pela Universidade de São Paulo (USP). Professora associada da Universidade Estadual de Maringá (UEM). Maringá, Paraná, Brasil. Avenida Colombo, 5790, Zona 7, CEP: 87020-900, Maringá, Paraná. E-mail: nmmkiouranis@gmail.com 


\section{Introdução}

Dedicamos o presente trabalho a um episódio da História da Química, a Alquimia, à qual não se tem dado a devida atenção por parte dos educadores, no meio acadêmico (BRIBIESCA; ROBLES, 2005). Além disso, professores e alunos, muitas vezes, desconhecem os caminhos que levaram à origem da Química (PARDO, 2002).

A "Grande Arte", conjugada como Alquimia, cria corpo por meio "[...] dos trabalhos de metalurgia, da magia estelar persa, do hermetismo egípcio e da interpretação mística da filosofia grega, a Alquimia, investigação sobre a natureza da matéria" (ALFONSO-GOLDFARB, 2001, p. 11). Tinha como objetivo principal o alcance da Grande Obra que visa a busca pela transmutação dos metais, ou seja, transformar metais menos nobres em ouro e prata, e a grande busca pelo elixir para cura de todos os males e o prolongamento da vida, embora tal objetivo nunca tenha sido atingido (TRAMER et al., 2007; MAAR, 2008).

De Alexandria, lugar onde se iniciou a prática alquímica (ALFONSO-GOLDFARB, 2001), vem a palavra Chemeia, cuja genealogia nos indica sua extensão, complexidade e obscuridade. Chemeia teria duas raízes completamente distintas: a primeira de origem egípcia, o termo Citem, remetendo à coloração negra; provavelmente por isso a alquimia ficou conhecida como "Arte Negra". O termo "negro" pode ser associado aos egípcios, pois o Egito era conhecido como "Terra Negra" pela coloração e solo fértil (BRIBIESCA; ROBLES, 2005). Ou ainda, o termo "negro" "[...] seria uma alusão à coloração tomada pelo metal após a calcinação ou oxidação (primeira etapa, ou etapa da morte na obra alquímica), evidenciando sua origem entre artesãos metalurgistas" (ALFONSO-GOLDFARB, 2001, p. 40). Ainda afirma a autora que a segunda raiz para o termo Chemeia seria o verbo Chew, derivado do grego que significa derramar, derreter, ao qual vincula a alquimia às práticas artesanais, atribuindo-lhe o caráter de trabalho prático.

Diante do contexto, este trabalho tem como objetivo apresentar a História da Alquimia desde sua origem em Alexandria, seu desenvolvimento em contextos variados em diversos lugares no mundo até o seu rompimento com os trabalhos de Robert Boyle, abrindo caminhos para a incorporação da Química como Ciência Moderna, além de contribuir para que o docente tenha uma visão mais elaborada sobre o processo de construção do conhecimento científico.

Esta pesquisa pretende, por meio da historiografia da ciência, escrever a história da Alquimia, visto que, na maioria das vezes, tal história é contada no livro didático e paradidático de forma ultrapassada, contribuindo para que o professor em sala de aula passe uma falsa visão de ciência ao estudante (BELTRAN; SAITO; TRINDADE, 2010) ou até mesmo evite tratar desse assunto.

A abordagem historiográfica permite analisar os episódios históricos, tendo como base os documentos originais (fontes primárias) e trabalhos de autores (fontes secundárias) (PEDUZZI; MARTINS; FERREIRA, 2012).

Podemos escrever a história da Ciência usando duas abordagens historiográficas distintas: a historiografia internalista, em que a ciência é encarada como autônoma, neutra e apresenta sua própria dinâmica, independente da sociedade que a gerou; ou a historiografia externalista, nessa perspectiva a ciência é tida como uma atividade humana, que deve ser compreendida 
considerando as questões sociais, política e econômica de sua época (BELTRAN; SAITO; TRINDADE, 2014).

Nesse trabalho a história da Alquimia foi recontada com a utilização de fontes secundárias e considerando as duas abordagens historiográficas, tanto a internalista como a externalista, pois assim é possível estudar como cada época construiu suas formas de ver o mundo (ALFONSO-GOLDFARB, 1994).

\section{A Alquimia Alexandrina}

Há várias vertentes sobre a origem da alquimia. Acredita- se que ela tenha se originado em Alexandria, entre os séculos III a.C. e I a.C., cidade fundada na foz do Nilo em 332 a.C., por Alexandre o Grande (BENSAUDE-VINCENT; STENGERS, 1992; VANIN, 1994; ALFONSOGOLDFARB, 2001; STRATHERN, 2002; LIMA; SILVA, 2003; MAAR, 2008; FARIAS, 2010; ALFONSOGOLDFARB et al., 2016).

A alquimia nasceu "[...] de uma combinação de artes práticas dos antigos, sobretudo dos egípcios e mesopotâmicos, de filosofia grega (tanto aristotélica como neoplatônica); e do misticismo hebraico e persa" (MAAR, 2008, p. 93). Para Maar (2008), a filosofia grega permitiu que a alquimia caminhasse em duas direções: a alquimia prática dedicada às práticas artesanais cultivadas nos templos egípcios; e a alquimia simbólica sendo encarada como uma continuação das práticas religiosas.

A cidade de Alexandria, em apenas dois séculos, tornou-se a maior cidade do mundo. Em relação à ciência, havia o Templo das Musas (ou Museu), cuja biblioteca, segundo a tradição, continha cerca de 400.000 a 500.000 livros na forma de rolos ou papiros, a qual proporcionou à Alexandria o maior centro do saber da antiguidade, atraindo estudiosos de todo o mundo mediterrâneo (MAAR, 2008; STRATHERN, 2002). Segundo Maar (2008), a alquimia nasceu em um momento de grande esplendor da Ciência grega, de modo que alguns nomes se destacam nesse período por sua atuação em Alexandria, dentre eles, menciona-se:

Euclides (c.300 a.C.), o mais importante matemático da antiguidade greco-romana; [...] Aristarco de Santos (c.310-230 a.C.), astrônomo, o primeiro a defender um modelo heliocêntrico; Eratóstenes da Cirenaica (c.276-194 a.C.), astrônomo que calculou a circunferência da Terra (achou $44.700 \mathrm{~km}$ em vez dos 40.000 corretos) em medidas feitas em Siene; Apolônio de Perga (c.262-190 a.C.), o 'Grande Geômetra', autor das 'Cônicas' (elipse, hipérbole e parábola); Diofante de Alexandria (c.250 a.C.), criador da Álgebra; Hiparco de Nicéia (? - 127), astrônomo e geógrafo, autor de um catálogo de 850 estrelas; Herão de Alexandria (c.62 a.C.), pioneiro da pneumática e da máquinas a vapor; Ptolomeu (ativo entre 127 e 145 d.C.), astrônomo do 'Almagesto" e da teoria geocêntrica. Fora de Alexandria, em Siracusa (Sicilia/Itália), viveu Arquimedes (c.290/280 a.C. - c.212/211 a.C.), o maior físico e matemático da antiguidade. Também na época helenística viveu Eudemo de Rodes (c.300 a.C.), discípulo de Aristóteles e provavelmente o primeiro historiador da ciência com a sua 'História da Geometria, Aritmética e Astronomia', incluída na obra de Teofrasto (MAAR, 2008, p. 94-95). 
Seguindo o que apontam os estudos de alguns historiadores, por exemplo, AlfonsoGoldfarb (2001) menciona que a formação da alquimia alexandrina se deu por influências babilônicas, egípcias, judaicas, persas e gregas. A influência do misticismo oriental, uma junção da magia e astrologia, proveniente de fontes babilônicas e persas, teria iniciado sua inter-relação por volta do século VI a.C. Nessa época, há evidências de que na religião astral caldeia, de acordo com seus ensinamentos, os corpos celestes, conforme sua posição, transmitiam boas ou más emanações à Terra. Isso possibilitou a associação dos "sete" deuses-planetas, com os respectivos metais conhecidos na época. Assim, o Sol passou a ser associado ao ouro, a Lua à prata, Vênus ao cobre, Mercúrio ao mercúrio, Marte ao ferro, Júpiter ao estanho e Saturno ao chumbo. Tanto a astrologia como a numerologia tentam, dessa maneira, relacionar o macro e o microcosmo, de modo que o macrocosmo relaciona-se a observações da meteorologia e calendário para fins agrários; enquanto o microcosmo está relacionado a pesos e medidas para fins de comércio.

Por meio de textos deixados por Zózimo de Panópolis (c.350-c.420), chegariam a nós informações sobre outros alquimistas anteriores a ele (PARDO, 2002; PRINCIPE, 2013), além de citar Bolos de Mendes (o Pseudo-Demócrito), Zózimo atribui Maria a Judia, a invenção de diversos aparatos de laboratório, entre eles o "banho maria", também considera que foram desenvolvidos por ela o alambique de três bicos, utilizado para obtenção de águas sulfurosas, e o kerotakis $^{1}$, um tipo aperfeiçoado de sublimador (FEDERMANN, 1972; MAAR, 2008; PÁEZ; GARRITZ, 2013; ALFONSO-GOLDFARB, 2016). Zózimo não era apenas um teórico, era também um prático com um vasto conhecimento químico. Por exemplo, ele conhecia o arsênico, que na época era definido como um "segundo mercúrio". Conforme Zózimo, com a ajuda do arsênico era possível transformar cobre em prata (FEDERMANN, 1972). Para Principe (2013), acredita-se que Zózimo tenha escrito vinte e oito livros dedicados à Alquimia, infelizmente grande parte de suas obras se perderam ao longo do tempo.

Na principal obra de Bolos de Mendes, "Physica et Mystica", consta de uma parte prática, relacionada à metalurgia, coloração dos metais, imitação das pedras preciosas e indicações envolvendo a obtenção de ouro e prata; e uma parte teórica sobre as leis fundamentais da alquimia (MAAR, 2008; BADILLO; MIRANDA, 2014). De acordo com Zózimo, Maria a Judia e Demócrito teriam sido discípulos do mago persa Ostanes (ALFONSO-GOLDFARB, 2016), que teria vivido na Pérsia por volta do século IV a.C., considerado profeta, místico e mago, admitindo que o conhecimento era adquirido por revelação (gnosticismo) (MAAR, 2008).

Antigamente a transmutação dos metais era sustentada pela teoria dos quatro elementos, tal explicação estaria desligada dos fenômenos do mundo real. Na verdade, a transmutação ocorria seguindo quatro etapas, começando pela tetrasoma (liga constituída por chumbo, estanho, cobre e ferro), que na sequência se dava às mudanças de cor: preto $\rightarrow$ branco $\rightarrow$ amarelo $\rightarrow$ vermelho. As etapas da transmutação da pedra que não é pedra, ou seja, a "pedra

\footnotetext{
${ }^{1} \mathrm{O}$ kerotakis é um tipo de fogão em cujo recipiente inferior é colocada uma substância que tende a evaporar por aquecimento, especificamente enxofre e mercúrio (FEDERMANN, 1972).
} 
filosofal", material de origem e composição desconhecida de aparência pétrea, que pode ser dissolvido (ALFONSO-GOLDFARB, 2001), são:

I.Melanose: é a primeira etapa da transmutação, leva a um material preto e corresponde à obtenção do tetrasoma, enegrecido na superfície por causa de oxidações (é a "obra em negro");

II.Leucose (obtenção de material branco): é a segunda etapa, que consiste essencialmente em: tetrasoma + vapores de As $\rightarrow$ liga superficial Cu/As (As como principal componente);

III.Xantose (produto amarelo): é a terceira etapa e correspondente ao tratamento do produto da leucose com o theion hydor (água divina ou água sulforosa), cuja preparação é descrita por Zózimo: é uma solução aquosa de sulfetos alcalinos ou alcalinos-terrosos;

IV.lose: é a etapa máxima da transmutação (a obra em vermelho), difícil de obter em função da multiplicidade de reações que podem ocorrer (MAAR, 2008, p. 101-102).

A primeira etapa da transmutação, conhecida também como a "obra em negro", simboliza a morte; a segunda etapa, a "obra em branco", refere-se à ressurreição, a nível operativo este é fenômeno da coagulação. As duas últimas etapas do processo de transmutação coroam a obra alquímica, ou seja, conduzem à Pedra Filosofal, sendo a primeira virtude da Pedra sua capacidade para transmutar os metais em ouro e também o principal objetivo dos alquimistas alexandrinos (ELIADE, 1974).

Uma possível explicação do que realmente ocorria nas etapas da transmutação torna-se difícil em função dos componentes que intervêm e das séries de reações que ocorrem, mas devem ser levadas em consideração as reações superficiais, a cinética das reações e outros fatores. Na concepção de C. G. Jung, essa sequência de etapas era chamada pelos latinos de "[...] nigredo - albedo - citrinitas - rubedo, sendo uma metáfora da individualização, cada etapa seria uma fase distinta da evolução psicológica do indivíduo" (MAAR, 2008, p. 102).

Os alquimistas alexandrinos classificavam as substâncias em três grupos: a) somata, eram ouro, prata, cobre, ferro, estanho, chumbo e as ligas metálicas; b) asomata eram as substâncias minerais - o óxido de arsênio, auripigmento $\left(\mathrm{As}_{2} \mathrm{~S}_{3}\right)$, realgar $\left(\mathrm{As}_{4} \mathrm{~S}_{4}\right)$, cinábrio $(\mathrm{HgS})$, mínio $\left(\mathrm{Pb}_{3} \mathrm{O}_{4}\right)$, nítron $\left(\mathrm{Na}_{2} \mathrm{CO}_{3}\right)$, as piritas, cadmia (óxido misto de $\mathrm{Sn}, \mathrm{Cu}$, e $\mathrm{As}$ ), magnésia, cianos (azurita) e crisocola (malaquita) e c) pneumata seriam as substâncias voláteis: o enxofre, o mercúrio e os sulfetos de arsênio. $O$ sal amoníaco foi incluído pelos árabes (MAAR, 2008).

Para Alfonso-Goldfarb (2001), após Zózimo a alquimia alexandrina aos poucos deixa de ter como objetivo a investigação da matéria e passa a adotar uma doutrina mística de caráter evocativo e intelectual. A prática dedicada ao laboratório, relacionada à investigação da matéria, passa a ser secundária "[...] e os conhecimentos alquímicos tornaram-se estanques" (ALFONSOGOLDFARB 2016, p. 23). A autora ainda afirma que os alquimistas alexandrinos são citados como autoridades máximas e irrefutáveis no assunto.

Somente alguns séculos depois, o conhecimento alquímico passa a ser retomado pela cultura árabe, para desvendar os novos mistérios da matéria (ALFONSO-GOLDFARB, 2001; ALFONSO-GOLDFARB et al., 2016). 


\section{A Alquimia Islâmica}

As atividades práticas, relacionadas ao tingimento de materiais e à manipulação de metais e também com uma medicina que continha um vasto receituário de remédios vegetais $\mathrm{e}$ minerais, chegaram ao mundo árabe. Algumas dessas atividades foram assimiladas e aglutinadas pelos mulçumanos, resultando na confecção de materiais e objetos favorecendo a riqueza comercial do império. Aos poucos, o conhecimento dessas atividades práticas foi entrelaçado a um corpo teórico produzido pelos "ismailis" e "sufis". Os "ismailis" seriam os filósofos dedicados a desvendar e estudar os segredos da matéria, enquanto os "sufis" seriam os estudiosos do pensamento filosófico e oculto (ALFONSO-GOLDFARB, 2001).

Para Alfonso-Goldfarb (2001), a alquimia islâmica se inicia no final do século VII, durante o califado de Omíadas. Segundo a tradição, o primeiro alquimista mulçumano foi o príncipe Khalid ibn Yazid, cuja atração pela alquimia foi tanta que mandou trazerem filósofos gregos do Egito a fim de que alguns escritos alquímicos pudessem ser traduzidos. Embora a origem da alquimia islâmica seja alvo de dúvidas e controvérsias, a maioria dos historiadores da química adota que a mesma originou-se a partir da alquimia praticada em Alexandria (FARIAS, 2010).

No vasto conhecimento da alquimia islâmica se sobressaem dois nomes, sendo eles: Jabir ibn Hayyan (720-815), mais conhecido como Geber ou Jabir e Abu Bakr Muhammad inb Zakariyya (865?-925), conhecido como Al-Razi ou Rases (PARDO, 2002; MAAR, 2008; FARIAS, 2010).

A obra "Teoria dos Balanços" de Jabir é uma das contribuições teóricas islâmicas à Alquimia, de modo que o termo "balanço" está relacionado a um equilíbrio de qualidades ou propriedades e não a um equilíbrio entre massas. A teoria dos quatro elementos de Aristóteles é aceita por Jabir com algumas adaptações, as quais considera a existência das quatro qualidades (o calor, o frio, o seco e o úmido). Por meio da combinação destas, haveria a formação de um composto; e a união de dois compostos resultaria novamente nos quatros elementos:

$$
\begin{aligned}
& \text { fogo = calor + seco + substância; } \\
& \text { ar = calor + úmido + substância; } \\
& \text { água = frio + úmido + substância; } \\
& \text { terra = frio + seco + substância (MAAR, 2008, p. 113). }
\end{aligned}
$$

No caso dos metais, o enxofre seria responsável pelas naturezas quente/seco, enquanto o mercúrio, frio/úmido. "Como ambos participavam na constituição de corpos metálicos, um destes deveria possuir um par de 'naturezas' externas e um par de internas, conforme as proporções de 'mercúrio' e de 'enxofre' em sua formação" (ALFONSO-GOLDFARB, 2001, p. 87). Assim, a transmutação só seria possível a partir de duas operações principais, a Barrani (exterior) e a Jawwani (interior), conforme as proporções do metal que se quisesse obter. Essa teoria desenvolvida pelos árabes, capaz de explicar a origem, a composição e a transformação da matéria, ficou conhecida como teoria enxofre-mercúrio (PARDO, 2002; ROBLES; BRIBIESCA, 2005; ALFONSO-GOLDFARB et al., 2016). 
De acordo com Farias (2010), além de Jabir, Rases foi outro alquimista de destaque, dedicando-se à alquimia médica, trazendo contribuições à ginecologia e oftalmologia. Rases foi o primeiro capaz de fazer uma distinção entre a varíola e o sarampo, tendo escrito vários trabalhos, dos quais apenas um, "O livro do segredo dos segredos", foi publicado em Berlim no ano de 1937 (FARIAS, 2010; MAAR, 2008; BADILLO; MIRANDA, 2014). A obra de Rases é dividida em três partes: substâncias, aparelhos e operações. As operações discutidas por Rases são: “[...] destilação, calcinação, dissolução, evaporação, cristalização, sublimação, filtração, amalgamação, e 'ceração' (conversão em sólidos pastosos ou fusíveis)" (MAAR 2008, p. 116).

Rases também, além dos três "espíritos" alexandrinos (enxofre, mercúrio e sulfetos de arsênio), cita um quarto - o sal amoníaco - obtido a princípio pelo esterco de camelo. Nas reações por ele praticadas são citados os ácidos conhecidos como águas fortes (MAAR, 2008). Propôs a teoria da matéria, segundo a qual existiam os cinco princípios eternos: "[...] o criador, a alma, a matéria, o tempo e o espaço" (FARIAS, 2010, p. 22). Segundo Rases, os corpos eram constituídos por partículas indivisíveis e pelos espaços vazios entre elas. Além disso, acreditava que seria possível ocorrer a transmutação dos metais apenas alterando as proporções dos princípios. Assim, a transmutação de um metal em outro ocorreria de acordo com as seguintes etapas:

A purificação de material de partida era a primeira operação a ser realizada. Seguia-se a fusão, através da qual o material era transformado numa espécie de amálgama e não soltava mais fumaça. Esse material era submetido, então, à operação de dissolução, a qual poderia envolver a ação de algumas 'águas agudas' que promoveriam a separação ou desintegração do material em suas partes mais sutis. Por fim era realizada a operação de coagulação ou solidificação, considerada como 'remoção da água'. Se o processo fosse bem sucedido o produto final seria o 'elixir' (ALFONSO-GOLDFARB et al., 2016, p. 27).

O "elixir" poderia converter metais comuns em ouro e também converter pedras não preciosas, como o quartzo e vidro, em pedras preciosas (esmeraldas e rubis) (FARIAS, 2010). As obras alquímicas de Jabir e Rases caminham em dois estilos distintos de aperfeiçoamento material e espiritual. Jabir representa um "[...] lado esotérico da alquimia, o simbólico-místico, uma gnose islâmica; enquanto que Rases corporifica o aspecto exotérico, o lado prático, experimental" (MAAR, 2008, p. 117).

Um dos pensadores a levantar críticas à alquimia foi o médico Abu Ali Al-Husayn ibn Sina (980-1037), mais conhecido como Avicena, cuja obra médica foi usada como base para o ensino de medicina na Europa até por volta do século XVI. Avicena acredita na teoria enxofre-mercúrio, usada para explicar a formação de diferentes metais, e que cada um deles seria formado por enxofres e mercúrios de diferentes tipos. Embora ele admitisse que era possível ocorrer a transmutação, criticava que a mesma não pudesse ser alcançada pela "Arte", mas sim, pela Natureza (ALFONSO-GOLDFARB et al., 2016).

\section{A Alquimia Chinesa}

Para Farias (2010), uma característica marcante da Alquimia Chinesa é que a mesma apresenta um aspecto místico, esotérico, dando maior atenção à transmutação dos metais. $\mathrm{A}$ transmutação de um metal menos nobre em ouro poderia ser uma metáfora para a 
transmutação interior do ser humano, que passaria de um estado impuro para um estado de superioridade. Os primeiros documentos a mencionar a prática alquímica chinesa cita que os falsificadores de ouro poderiam ser punidos com uma execução pública.

Por meio dos princípios da filosofia taoísta, foi possível o surgimento de equilíbrio na Alquimia Chinesa. Para obter tal equilíbrio, surge o termo "elixir", sendo capaz de transportar as qualidades de um corpo a outro. Os alquimistas chineses estavam preocupados em buscar o caminho para sua própria superação, para obter o equilíbrio de si mesmo com o todo. De acordo com a tradição com base na lei de Tao, "[...] o taoísta deveria despojar-se de todos os bens materiais, e o ouro não tinha valor de troca na antiga China" (ALFONSO-GOLDFARB et al., 2016, p. 65).

Lao Tze foi o fundador do taoísmo no século VI, que constitui uma filosofia de vida, o termo "Tao" refere-se ao caminho do universo, podendo ser atingido através do equilíbrio entres os opostos. Dessa maneira, a combinação de Yin (feminino e passivo) e Yang (masculino e ativo), gerava o mundo. Para os chineses, seriam os cinco elementos água, terra, fogo, madeira e metal, em que cada um deles conteria os princípios Yin e Yang, em menor ou maior quantidade conforme sua natureza (ALFONSO-GOLDFARB et al., 2016; LIMA; SILVA, 2003).

Um dos importantes alquimistas chineses é Ko Hung (284-343), autor de "Pao-Po-Tsu" (Mestre que guarda a simplicidade), obra considerada longa e o mais importante tratado alquímico, descreve medicamentos, operações práticas e matérias mágicas (MAAR, 2008).

\section{A Alquimia na Europa Medieval}

A Idade Média parece ser o cenário ideal para o desenvolvimento da Alquimia Europeia (MAAR, 2008) e pode ser dividida em duas fases: a alta idade média que está relacionada à formação dos reinos germânicos no século $V$, até a consolidação do feudalismo, entre os séculos IX e XII; e a baixa idade média que se entende pelo crescimento das cidades, pela expansão territorial e pelo florescimento do comércio, que vai até o século XV (FARIAS, 2010).

Para Alfonso-Goldfarb (2001), um vasto conhecimento antigo chegará à Europa através da civilização árabe, numa visão interpretada e aumentada pelos pensadores mulçumanos. Anterior ao século XII, a absorção dos conhecimentos árabe e grego para a Europa Ocidental, alguns nomes se destacam por seu interesse em traduzir alguns originais clássicos para a língua latina, dentre eles temos Gerberto de Aurillac (no século X) e Constantino de África (século XI).

No ramo da química, embora nessa época ainda não houvesse se estabelecido como ciência moderna, ocorreram as grandes traduções, como o "Compositiones ad tinguenda". A obra se constitui por um receituário sobre como lidar com metais e tinturas, semelhante ao encontrado na antiga literatura egípcia, mas se diferencia por ser escrito numa linguagem clara e objetiva, capaz de informar os especialistas nessas artes. A primeira obra alquímica foi traduzida por Robert de Chester em 1144 para o latim: "Livro da Composição da Alquimia (De compositione alchemiae)", relatando os ensinamentos sobre a "Arte". Acredita-se que seja a primeira obra sobre alquimia escrita por Khalid ibn Yazid. E também Gerard de Cremona traduziu algumas obras, dentre elas: os "Setenta Livros" da obra jabiriana, dois livros de Rases "De 
aluminibus et salibus" e "Liber luminis luminum", "Segredos dos Segredos", "Segredo da Criação" de Balinus, "Tábua de Esmeralda", "Turba philosophorum" e o tratado de Avicena "De Anima". No final do século XII, a maioria dos trabalhos em alquimia encontrava-se sob posse dos europeus (ALFONSO-GOLDFARB, 2001).

O estudo da matéria foi uma das preocupações da filosofia árabe, e no contexto europeu na baixa idade média estavam mais preocupados com a manipulação da natureza do que a teoria. Essas questões são retomadas pelo escolasticismo por meio de duas correntes, mais tarde denominada "via antiga" da filosofia. A primeira corrente, denominada "experimentalista", inicia- se com Robert Grosseteste (1168-1253), bispo de Lincoln e mestre dos franciscanos. Grosseteste foi um severo crítico daqueles que tentavam buscar em Aristóteles reflexos da teologia cristã, e também foi estudioso do platonismo de Santo Agostinho e do aristotelismo de Avicena (ALFONSO-GOLDFARB, 2001).

A segunda corrente da "via antiga" atribui-se a Alberto Magno (c.1193-1280), o "Doctor universalis", grande interpretador de Aristóteles, nascido na Bavária, tendo realizado seus estudos em Pádua, Bolonha e na Universidade de Paris e sendo um dos primeiros a incluir as ideias de Aristóteles no ensino ministrado nas universidades europeias, ligadas às grandes catedrais e mosteiros (ALFONSO-GOLDFARB, 2001). Alberto Magno, em seu tratado "De mineralibus et rebus metallicis" sobre mineralogia, refere-se à alquimia e aos alquimistas concordando com Avicena sobre a transmutação dos metais acontecer apenas pela Natureza (ROBLES; BRIBIESCA, 2005). Para Alberto, a formação dos metais e minerais ocorria no interior da terra a partir de "exalações" úmidas e secas. As reflexões de Alberto Magno sobre alquimia levaram vários pensadores a se interessarem pela "Arte", sendo Roger Bacon o primeiro a atribuir à alquimia tal valor e a reconhecê-la como ciência do mais alto nível (ALFONSOGOLDFARB et al., 2016).

Segundo Alfonso-Goldfarb (2001), Roger Bacon (1214-92) nasceu em Somerset, na Inglaterra, estudou e lecionou em Oxford e também foi professor na Universidade de Paris, sendo um dos primeiros a ensinar Física e Metafisica de Aristóteles, o que antes era proibido pela Igreja. A partir de 1247, iniciou seus estudos com base na obra de alguns "homens sábios" interessados em ciência natural, dentre eles Grosseteste. Nessa época, Bacon decide entrar para a ordem dos franciscanos. Roger Bacon tem maior interesse em conhecimentos práticos dos "experimentadores", "[...] entre os quais estariam incluídos apotecários, alquimistas, engenheiros e astrólogos" (ALFONSO-GOLDFARB, 2001, p. 113). É importante destacar que os trabalhos do filósofo escolástico tomaram uma forma mais direcionada à reflexão e síntese do que à elaboração de invenção de novas ideias, ficando conhecido como um organizador do saber.

Segundo Maar (2008), a contribuição mais importante de Roger Bacon no campo da Ciência foi a recomendação de unir o empirismo à experimentação e ao desenvolvimento matemático, postura que o coloca como o precursor da Revolução Científica dos séculos XVI e XVII. Além disso, o referido filósofo classificou as ciências da seguinte maneira, conforme apresentado no Quadro 1. 
Quadro 1: Classificação das ciências de acordo com Roger Bacon.

\begin{tabular}{|l|l|}
\hline & Perspectiva (a nossa óptica); \\
& Astronomia (operativa e judicial); \\
& Ciência dos pesos (a nossa mecânica); \\
& Alquimia; \\
& Medicina; \\
& Agricultura; \\
& Ciência experimental (uma ideia original de Bacon). \\
\hline
\end{tabular}

Fonte: Maar (2008, p. 149).

Bacon, pelo seu grande apreço à Alquimia, classificou-a em especulativa que "[...] trata da formação das coisas, a partir dos elementos"; e prática que "ensina a produzir metais, cores e pigmentos, medicamentos, etc." (MAAR, 2008, p. 149). A Alquimia prática, segundo Bacon, era a mais importante das ciências, tanto que em sua obra "Opus Tertius" descreve as chaves da Alquimia, de modo que o termo "chaves" significaria as operações, tais como: "[...] purificação, destilação, ablução, calcinação, ustulação, moagem, mortificação, sublimação, proporção, decomposição, solidificação, fixação, liquefação, projeção e depuração" (MAAR, 2008, p. 149).

Em relação à formação dos metais, Bacon também concorda com as ideias de Avicena, de que os metais são constituídos de formas puras de "enxofre" e "mercúrio" em diferentes proporções, sendo o ouro a mais perfeita proporção. Também acreditava na transmutação dos metais, segundo ele "[...] os metais que não tiverem o balanço perfeito deverão ser 'tratados' com os 'remédios' adequados, para que obtenham o equilíbrio e a perfeição do ouro" (ALFONSO-GOLDFARB, 2001, p. 119). Ou seja, a suposta cura do metal seria promovida por meio de um "remédio" ou "elixir", assim a alquimia visaria a busca desse elixir, que poderia tanto aperfeiçoar os metais, como também trazer a cura do homem prologando sua vida. O "elixir" seria constituído por uma espiritualização da matéria e para sua obtenção Bacon sugere uma série de possibilidades (calcinação, pulverização, sublimação), a que o material de partida deve ser submetido. A grande busca pelo "elixir" seria a principal característica da alquimia europeia (ALFONSO-GOLDFARB, 2016).

Para Alfonso-Goldfarb (2016), a ideia de elixir estará presente nos pensamentos dos mais importantes alquimistas medievais: Geber, Arnaldo de Vilanova, Raimundo Lúlio e João de Rupescissa, sendo que cada um deles traria novas concepções ao conhecimento. Dessa forma, Geber, em sua obra, contribui para incentivar a aplicação dos métodos metalúrgicos na alquimia, tais como a copelação. Já as obras de Arnaldo de Vilanova, Raimundo Lúlio e João de Rupescissa contribuem "[...] para divulgar a utilização de remédios preparados a partir de metais, e para difundir a utilização da aqua vitae (solução com alto teor alcoólico) como poderoso medicamento" (ALFONSO-GOLDFARB, 2016, p. 33).

O que conhecemos hoje como álcool já vem sendo utilizado como remédio desde o século XII. Raimundo Lúlio em sua obra traz a ideia de que ao destilar várias vezes a aqua vitae, seria obtido um espírito tão perfeito que poderia ser comparado aos céus, algo para nós hoje como um conhaque muito forte, seria a quintessência extraída do vinho. Também acreditava-se que a quintessência poderia ser extraída mediante a destilação de diferentes materiais, para poder ser utilizada como um poderoso medicamento (ALFONSO-GOLDFARB, 2016). 
A concepção de que cada coisa da Natureza guardaria em si uma virtude, com base em que o universo seria uma rede de relações, viria a ser difundida no Renascimento, sendo Paracelso um dos principais pensadores a se basear nessas ideias sobre a composição e transformação da matéria (ALFONSO-GOLDFARB, 2016).

\section{Paracelsus e a Iatroquimica}

Paracelsus foi o responsável pela segunda Revolução Química, sendo que o autor da primeira foi Roger Bacon, o qual propôs o retorno das obras aristotélicas, como mencionado anteriormente (MAAR, 2008). Paracelsus, além de abandonar Aristóteles, também deixa de lado todas as autoridades antigas, predominando um retorno aos próprios fatos, o que gera um predomínio do experimento por volta do século XVI (BADILLO; MIRANDA, 2014). Para Maar (2008, p. 215) é:

[...] um século de grande atividade prática, da metalurgia à farmacologia e aos prenúncios da Química Inorgânica moderna. A Química é ainda em essência uma química atrelada à medicina de um lado e à metalurgia de outro, mas já há prenúncio de uma química independente, preocupada com os estudos das substâncias, suas propriedades e maneiras de obtenção, por elas próprias.

Conforme podemos verificar, Paracelsus propunha uma Química desvinculada e independente de suas aplicações na medicina e na metalurgia, de modo a dar um maior direcionamento ao que se refere às propriedades das substâncias, assim como os processos para sua devida obtenção.

Theophrastus Bombastus von Hohenheim (c. 1490-1541) assinava seus trabalhos sobre o pseudônimo de Phillipus Aureolus Paracelsus (VANIN, 1994; CHASSOT, 1994; PORTO, 1997; CECON, 2013), tendo aprendido medicina, mineralogia e química com o pai Wilhelm von Hohenheim (? - 1534). Ainda jovem, Paracelsus vai para a Escola do Mosteiro de Santo André, tornando-se amigo do grande alquimista da época, o bispo Eberhard Baumgartner, influenciador na sua vida e obra. Para Farias (2006), Paracelsus percorreu a Europa por vários anos, desenvolvendo estudos sobre mineração, medicina e alquimia (ROBLES; BRIBIESCA, 2005).

De acordo com Strathern (2002), Paracelsus foi a figura mais importante da latroquímica, prática desenvolvida entre a metade do século XVI até o século XVIII (PARDO, 2002; SANTOS et al., 2012), o termo "iatro" origina-se do grego que significa "médico", e tem como objetivo "[...] estabelecer a química como o cerne da prática médica" (STRATHERN, 2002, p. 71). Embora Paracelsus acreditasse que a alquimia pudesse produzir ouro algum dia, declarou que a prática alquímica estaria perdendo tempo nessa tentativa. Segundo ele, a alquimia deveria estar voltada "[...] para a medicina para produzir remédios químicos para moléstias e doenças, com a preparação de remédios específicos para o tratamento de doenças específicas. Assim a medicina iria se tornar uma ciência, em vez da arte vagamente duvidosa que parecia ser então" (STRATHERN, 2002, p. 71).

$\mathrm{Na}$ época, as ideias mais difundidas sobre as causas da saúde física e mental eram derivadas da "teoria dos quatros humores", segundo a qual o equilíbrio entre os quatro humores 
resultaria no corpo humano saudável (FARIAS, 2006; PORTO, 1977). Segundo Porto (1997), esses humores estariam relacionados com os quatros elementos e quatro qualidades primárias, que seriam: o sangue relacionado à qualidade quente, a fleuma ao úmido, a bílis amarela (cólera) ao seco e bílis negra (melancolia) ao frio. O desequilíbrio entre esses humores ou entre essas qualidades resultaria nas doenças, e a suposta cura seria ministrar "[...] a qualidade momentaneamente em falta" (PORTO, 1977, p. 569), ou então retirar a qualidade que estaria em excesso. Por exemplo, com o objetivo de abaixar a febre, uma vez que tal sintoma era resultado de excesso de sangue, o tratamento adequado seria a prática da sangria. Cada um desse humores, por sua vez,

tinha sede em um órgão do corpo humano: o sangue no coração, a fleuma no cérebro, a cólera no fígado e a melancolia no baço. [...] os quatros humores também estavam ligados, nessa concepção, às quatro estações do ano, às quatro idades do homem e aos quatro pontos cardeais, sendo ainda controlados pelos quatro maiores planetas então conhecidos: lua, marte, júpiter e saturno, criando assim uma grande barafunda filosófico-científica lou antes, pseudocientifica) que verdadeiramente atravancava a evolução da prática médica e conduzia a prescrições mais absurdas, como a conhecida prática das sangrias [...] (FARIAS, 2006, p. 23).

Para explicar a constituição da matéria, Paracelsus modificou as ideias antigas dos alquimistas árabes sobre a composição dos metais em termos dos opostos mercúrio e enxofre. A teoria fundada por Paracelsus ficou conhecida como "tria prima", além do mercúrio e enxofre, ele adicionou um terceiro princípio, o sal. Assim, o enxofre conteria o princípio da inflamabilidade; o mercúrio da volatilidade; e o sal fornecia a matéria cor, solidez e imutabilidade (TRAMER et al., 2007). Além de explicar a composição dos metais, a "tria prima" explicaria a constituição de todas as substâncias (PORTO, 1997; ROBLES; BRIBIESCA, 2005; FARIAS, 2006; TRAMER et al., 2007; CECON, 2013; BADILLO; MIRANDA, 2014; ALFONSOGOLDFARB et al., 2016).

A teoria dos três princípios permite fazer uma analogia com o processo de destilação, no qual se observa a separação dos corpos no que seriam suas partes constituintes: a parte combustível seria o princípio enxofre; a parte líquida e não inflamável seria o mercúrio; e o resíduo sólido que permanece no fundo do frasco de destilação corresponderia ao sal. No esquema de analogias cósmicas através do qual Paracelso enxergava o Universo, os três princípios podiam ainda ser associados a outras tríades, tais como alma-espírito-corpo, ou mesmo à Santíssima Trindade (ALFONSO-GOLDFARB et al., 2016, p. 42).

Embora haja alguns aspectos da obra de Paracelsus que hoje poderiam ser considerados "não científicos", acredita-se que Phillipus Aureolus Paracelsus foi um reformador da medicina e da farmacologia. De acordo com Farias (2006), Paracelsus foi o primeiro a prescrever um tratamento para sífilis sob administração de compostos de mercúrio (PARDO, 2002), também teria produzido drogas à base de éter, sendo utilizada para fins anestésicos, além disso, descreveu tratamento para insônia que consistia na administração de uma solução de ópio em suco de laranja e limão. 
Nos dias atuais a farmácia moderna muito se beneficia de compostos que Paracelsus investigou e receitou aos seus pacientes, tais como:

sais de zinco e cobre, compostos de chumbo e magnésio etc. O uso de derivados do arsênio e do antimônio no tratamento de casos de câncer e lepra, derivados do arsênio para doenças de pele, e o uso de sulfato e óxido de zinco, atualmente utilizados para o tratamento de infecções cutâneas (o óxido de zinco é muito utilizado em formulações de 'talcos' para os pés) estão entre o arsenal terapêutico utilizado por Paracelsus (FARIAS, 2006, p. 64).

Segundo os paracelsistas, a terra era vasto laboratório químico, "[...] o que explicava a origem dos vulcões, das fontes termais, das fontes de montanha e o crescimento dos metais" (DEBUS, 2002, p. 26). Para Henri de Rochas (fl. 1620-1640), o calor de nascentes de água mineral era o resultado da reação do enxofre com um sal nitroso na terra. Edward Jorden (1569-1632), com uma explicação mais abrangente, descreveu que o crescimento dos metais ocorria pelo processo alquímico da "fermentação", sendo definida como uma reação exotérmica sem necessidade do ar. Segundo Jorden, isso era a causa do crescimento inorgânico, e esta nova fonte de calor permitia compreender os vulcões e as correntes de montanha (DEBUS, 2002).

Mesmo que a ideias de Paracelsus e seus seguidores em relação ao estudo da Natureza tivessem grande influência no século XVII, elas não foram capazes de substituir o aristotelismo. A partir do século XVII, desenvolveram-se novas ideias, diferentes tanto daquelas dos paracelsistas quanto das dos aristotélicos. Surge então o mecanicismo, cuja concepção acredita que o universo fosse uma grande máquina (ALFONSO-GOLDFARB et al., 2016).

\section{Boyle e os caminhos para a Química Moderna}

Robert Boyle (1627-1691) nasceu na Irlanda, no castelo de Lismore, oriundo de família nobre, sua formação acadêmica ocorreu, inicialmente, em casa e em seguida foi para o Eton College. Boyle completou seus estudos por viagens a França, Itália e Suíça. Durante sua formação inicial foi escritor no campo da moral, filosofia e religião. Anos depois tem uma atenção maior para com a Química, construindo um laboratório em sua casa, dedicando-se à prática experimental, tendo como objetivo incorporar a Química no contexto da nova filosofia natural e derrubar a ciência antiga que era vista como oculta e mística (ROBLES; BRIBIESCA, 2005; ANUNCIAÇÃO et al., 2014).

É com os trabalhos de Boyle sobre a transformação da matéria que se rompe com o paradigma da Alquimia e impõe a Química mecanicista, "[...] integrando-se à nova Filosofia Natural, isto é, ao mecanicismo da ciência dos modernos" (FREZZATTI Jr., 2005, p. 149). É importante destacar que Robert Boyle entrou pelo estudo da química, pela porta da Alquimia e possui uma grande quantidade de trabalhos com riqueza de detalhes. Não nos cabe descrever em detalhes e muitos menos fazer um resumo geral de sua obra, mas sim escolher tópicos mais relevantes, os quais proporcionaram introduzir a química entre as chamadas "ciências mecanicistas" (ALFONSO-GOLDFARB, 2001).

É comum os livros didáticos e paradidáticos associarem Robert Boyle à Lei de Boyle, ensinada durante os estudos dos gases. Mas antes de postular essa lei, Boyle trouxe 
contribuições para o desenvolvimento da Química, desenvolvendo uma teoria corpuscular da matéria, trouxe também uma definição para o termo elemento mais próxima da que conhecemos hoje, e criou a bomba de vácuo, proporcionando estudos importantes sobre a matéria (BIGHETTI, 2019).

Na obra "Químico Céptico" (1661), Boyle definiu elemento como:

[...] certos corpos primitivos e simples, perfeitamente puros de qualquer mistura, que não são constituídos por nenhum outro corpo, ou uns pelos outros, que são os ingredientes a partir dos quais todos os corpos que chamamos misturas perfeitas são compostos de modo imediato, e nos quais estes últimos podem ser finalmente resolvidos[...] (BENSAUDEVINCENT; STENGERS, 1992, p. 53).

Segundo Bighetti (2019), para definir o termo "elemento" Boyle partiu da observação de que muitas substâncias podem ser decompostas em substâncias mais simples. Dessa forma, Boyle concluiu que elemento pode ser qualquer substância que não pode ser decomposta em uma substância mais simples.

Em seus estudos sobre o ar, Boyle verificou a relação entre volume e pressão do ar, conhecida como Lei de Boyle. Com esse estudo há discussões sobre as provas para existência do vácuo - tese rejeitada por Aristóteles e alguns mecanicistas do século XVII - que viriam a ser afirmadas somente com os estudos realizados desde Torricelli até Pascal. Também nesse período foi desenvolvida uma máquina capaz de "produzir vácuo", ou seja, uma bomba capaz de retirar ar dos recipientes, ideia contestada por alguns pensadores. A existência do vácuo é fundamental para as ideias de Boyle sobre a composição da matéria e, segundo o químicoalquimista, as partículas, sejam elas constituintes universais da matéria, se movimentariam constantemente no vácuo (ALFONSO-GOLDFARB, 2016). Segundo Alfonso-Goldfabr (2001), Boyle, com auxílio da engenhosidade instrumental de R. Hooke e pelo laboratorista Greatorex, construiu uma bomba a vácuo com uma riqueza de detalhes. Tal equipamento consistia de uma cúpula de vidro hermeticamente fechada por uma chapa de latão. $O$ ar era retirado através de uma bomba de cremalheira a pinhão, sendo operada manualmente por meio de válvulas. Um barômetro era acoplado à bomba para efetuar as medidas de variação de pressão do ar.

\section{Boyle e a Filosofia Corpuscular}

Em seus primeiros trabalhos, "Seraphic Love ou The Theological Uses of Natural Philosophy", combinando ciência com religião, nota-se que Boyle não fazia muito o uso da matemática como linguagem. Era muito comum em seus experimentos fazer longas descrições incluindo ilustrações dos instrumentos realizados que pudessem, através da linguagem comum, atingir o homem e todos os interessados, sem ter a necessidade de uma iniciação para tal (ALFONSO-GOLDFARB, 2001; CÁRDENAS, 2005). Segundo Frezzatti Jr (2005), a prática experimental, para o químico e filósofo Boyle "[...], não era mais um meio de ligar o macro e o microcosmos, mas um meio para comprovação de teorias e elaboração de hipóteses. A experimentação no laboratório não era mais a síntese do Cosmos, mas a análise das partes de uma máquina, isto é, do Universo (p. 150)". 
Na obra "The Sceptical Chymist", escrita na forma de diálogo platônico, debatendo as ideias aristotélicas, espagiristas e filosofia natural, Boyle, por meio de Carneades e suas próprias experiências, critica a teoria dos três princípios, dizendo que estes não existiriam na realidade. Por meio de uma análise química desses compostos, conclui que as substâncias mais simples "[...] em que tais compostos se dividem, varia, não somente em número (às vezes superior, às vezes inferior a três), como também no tipo de substância básica encontrada nos diferentes compostos" (ALFONSO-GOLDFARB, 2001, p. 169). Nesse sentido, não existiria a homogeneidade dos três princípios básicos, então tal concepção "tria prima" não pode ser considerada como forma universal da matéria.

Para Carneades, os três princípios deveriam ser substituídos pela hipótese corpuscular sobre a formação da matéria. De acordo com Alfonso-Goldfarb (2001, p. 169), os corpúsculos ou partículas,

agregados de maneiras diversas, responderiam de maneira racional, aos problemas crescentes que a teoria dos três 'princípios' vinha enfrentando no confronto com a experimentação. Essas diferentes aglomerações corpusculares poderiam combinar-se de maneiras infinitas garantido resposta em casos nos quais na análise química detecta-se um número distinto de três substâncias básicas num composto. Assim como garantiria uma imensa quantidade de substâncias básicas, o que resolveria a questão da heterogeneidade na formação de diferentes compostos.

Tal hipótese corpuscular é a chave para introduzir a química à nova ciência, tida como mecanicista e, assim, eliminar a "tria prima" que já se encontra desgastada e também a teoria dos quatro elementos (ALFONSO-GOLDFARB, 2001). Boyle, em seus textos "The Origins of Forms" e "Sceptical Chymist", classifica os processos envolvendo a transformação da matéria em três níveis: Prima naturalia - entidade fisicamente indivisível, extremamente pequena e sólida, capaz de mover através do vácuo, criando aglomerados firmes e coesos a ponto de persistirem em soluções e outras operações (ALFONSO-GOLDFARB, 2001). Corpúsculos secundários: seriam capazes de transmitir certas características imutáveis às substâncias, formando aglomerados maiores, isto é, as substâncias compostas com graus de complexidade variados. Nesse nível seria possível ocorrer a operação de transmutação; e Substâncias compostas: compostos heterogêneos e que podem ser facilmente recombináveis, nível em que ocorrem as reações químicas (FREZZATTI Jr, 2005).

Em um dos capítulos de sua obra intitulado "Redintegration of Nitre (Physilogical Essays)", Boyle menciona que o salitre se decomporia pela ação do fogo "[...] no que ele chamou de 'nitron volátil' (ácido nítrico condensado) e 'nitron' fixo (carbonato de potássio, gerado pelo carvão usado no aquecimento" (ALFONSO-GOLDFARB, 2001, p. 186). A recombinação destas substâncias possibilitaria a obtenção do salitre, no entanto, com perdas do peso original. A respeito desse experimento, Boyle conclui que essa reação poderia ser reversível, o que confirma mais uma vez a teoria corpuscular. A reversibilidade das reações era algo impensável para os químicos da época. A prata dissolvida por ácido nítrico (aqua fortis), por exemplo, era entendida por Helmont como uma simples mistura, pois a prata seria recuperada no processo. Boyle vai contra essa ideia, dizendo que na verdade o composto final não é mais prata pura, mas 
um sal de origem ácida agregado no metal, aumentando o peso inicial, o que confirma a hipótese dos corpúsculos secundários. "Estamos diante de um significativo avanço para a futura teoria das reações" (ALFONSO-GOLDFARB, 2001, p. 187).

Para Cecon (2010), os corpúsculos se agrupam em agregados e a posição desses corpúsculos em relação a outros é chamada de textura. A textura do agregado é a responsável pela ação de um pedaço de matéria em outro, assim a matéria adquire uma nova característica diferente daquela presente nos corpúsculos iniciais (BOYLE, 2017). Com o rearranjo dos corpúsculos é possível construir novos agregados, assim Boyle conclui que qualquer coisa pode se transformar em outra e que não existe um corpo simples. Para Boyle "[...], todos os corpos são compostos por agregados de corpúsculos" (CECON, 2010, p. 49). Deste modo, esses agregados, ao interagir com outros agregados, adquirem características, qualidades que não estão presentes nos corpúsculos (ZATERKA, 2012).

Foi por meio dos experimentos alquímicos que Boyle trabalhou para poder refutar as antigas doutrinas de formas substanciais. Para Boyle, a química era o modo de ler o livro da natureza, por meio dela seria possível derrubar as antigas crenças (hipóteses) e sustentar novas. Dentro da história da química, há uma divisão dos historiadores da ciência, por não considerarem Boyle como mecanicista, mas sim, como um químico ou até mesmo um alquimista. Dentre diversos motivos para contrapor o pensamento químico ao mecanicista está o fato de que Boyle reduz muitas vezes a explicação do mundo ao agrupamento das partes (CECON, 2010, p. 9).

Para Alfonso-Goldfarb et al. (2016), as ideias mecanicistas de Boyle sobre a composição e as transformações da matéria não foram aceitas pelas maiorias dos químicos da época. No final do século XVII até o final do XVIII, as concepções que predominaram entre os químicos consistiam na existência de um princípio constituinte da matéria, denominado como o flogístico (ou flogiston) “[...] que seria uma substância impalpável presente em certos corpos inflamáveis, mas que, ao escapar destes, através da combustão, poderia ser transmitida a outros corpos tornando-os combustíveis" (ALFONSO-GOLDFARB, 2001, p. 201).

Para Beltran, Saito e Trindade (2010), o flogístico poderia ser comparado ao fogo, mas também era ingrediente dos corpos, sendo capaz de promover a transformação da matéria. $\mathrm{Na}$ combustão, por exemplo, os materiais, sejam vegetais ou animais, ao queimarem liberariam flogístico para o ar. Já na calcinação, os metais ao queimarem liberariam flogístico para o ar e deixariam uma cinza, a cal. Mas, também seria possível regenerar os metais pela união de materiais ricos em flogístico, a cal, por exemplo.

Dentro da História da Química, no período anterior a Lavoisier, que vai do final do século XVI até o início do século XVII, a então chamada "teoria do flogístico" alcançou seu sucesso, defendida por George Ernst Stahl (1659/60-1734). Tal teoria baseava-se na existência de um princípio que poderia ser componente da matéria, denominado flogístico. Por apresentar

\footnotetext{
${ }^{1}$ De acordo com Alfonso-Goldfarb et al. (2016) George Ernst Sthahl não foi o primeiro a usar o termo "flogístico". Estudiosos como Van Helmont, Becher e Boyle utilizaram esse termo em suas obras para designar um princípio responsável pela inflamabilidade.
} 
qualidades de inflamabilidade, esse princípio seria responsável pelos fenômenos relacionados à queima de materiais e também se encontrava associado a outros princípios elementares. Dessa maneira, a teoria do flogístico foi muito usada para explicar a combustão dos materiais (ALFONSO-GOLDFARB, et al., 2016).

\section{A ruptura do saber alquímico}

A obra de Roger Bacon mostra o momento em que Alquimia se instala no mundo europeu enquanto a obra de Robert Boyle marca o rompimento de tal crença, o que não significou a instauração da química moderna, "[...] mas um caminho aberto para esta: uma espécie de vazio onde o cosmo 'mecanicista' se delinearia e geraria as ciências modernas" (ALFONSO-GOLDFARB, 2001, p. 205). Tanto Bacon como Boyle são representantes de formas de pensar importantíssimas de suas épocas, mas não precursores da época seguinte. Dentro da História e Filosofia da Ciência, essa forma de interpretar os conhecimentos humanos faz parte da historiografia moderna, sendo inútil buscar percussores e descendentes, pois, "[...] partindo-se da tese de que o saber é construído e não dado naturalmente, seria inútil buscar uma linha regular dentro deste" (ALFONSO-GOLDFARB, 2001, p. 205). Ao longo da história, cada época teria trabalhado com o saber de acordo com suas particularidades históricas, seria um desrespeito de nossa parte com a temporalidade inerente a cada época tentarmos construir uma espécie de história.

Embora grande parte da nomenclatura, dos equipamentos e dos processos de manipulação sejam os mesmos, a forma e a finalidade de sua utilização serão extremamente diferentes para um alquimista e para um químico, ou seja, a mesma solução salina, o mesmo ácido usado por um e por outro terá conceitos e significações distintos (ALFONSO-GOLDFARB, 2001). Podemos explicar essa questão por meio da teoria da incomensurabilidade, proposta por T. S. Kuhn (2000), filósofo e historiador da ciência, segundo o qual não haveria maneira de comparar, sob um mesmo padrão, conceitos e ideias que apresentam uma certa semelhança, mas provenientes de escolas de pensamento divergentes. Uma das razões para isso é que o tratamento sofrido pelo conteúdo de uma teoria ultrapassada, à luz de ideias baseadas em uma nova teoria, a transforma conceitualmente, tornando-a incomensurável, isto é, não proporcional ou comparável a sua forma original.

Em sua obra "A estrutura das revoluções científicas", Thomas S. Kuhn procurou apresentar um modelo para o desenvolvimento da ciência com base nos momentos de grandes mudanças conceituais, que seriam chamados de revoluções científicas. Assim, propôs a existência de momentos de rupturas no processo do desenvolvimento do conhecimento científico. Essa descontinuidade na ciência foi justificada por meio da noção de "paradigma" (BELTRAN et al., 2014).

Para Kuhn (2000, p. 13), paradigmas são “[...] as realizações científicas universalmente reconhecidas que, durante algum tempo, fornecem problemas e soluções modelares para uma comunidade de praticantes de uma ciência". Esse período no qual os problemas são resolvidos pelo paradigma, Kuhn denominou de "ciência normal". Para esse autor (2000, p. 29): 
A "ciência normal" significa a pesquisa firmemente baseada em uma ou mais realizações científicas passadas. Essas realizações são reconhecidas durante algum tempo por alguma comunidade científica especifica como proporcionando os fundamentos para sua prática posterior. Embora raramente na sua forma original, hoje em dia essas realizações são relatadas pelos manuais científicos elementares e avançados. Tais livros expõem o corpo da teoria aceita, ilustram muitas (ou todas) as suas aplicações bem sucedidas e comparam essas aplicações com observações e experiências exemplares.

Para Moreira e Massoni (2009), existem também os problemas extraordinários, anomalias ou pesquisa extraordinária, que aparecem devido ao avanço da ciência normal. As anomalias se acumulam levando o paradigma a uma crise, isso leva à formulação de teorias novas forçando a comunidade científica a uma transição para um novo paradigma. Usando a linguagem de Kuhn (2000), digamos que ocorreu uma revolução científica. Para Silveira et al. (2019), a revolução científica é a mudança descontínua de um paradigma para outro, criando assim uma instabilidade gerando crises e anomalias. "Uma anomalia será considerada potencialmente séria se for capaz de desestruturar os próprios fundamentos do paradigma e levá-lo ao desenvolvimento de várias faces, desestruturando-o de tal modo que" (SILVEIRA et al., 2019, p. 4) torna-se necessário o surgimento de um novo paradigma que seja capaz de promover a revolução científica.

\section{Considerações Finais}

Sabemos que todo conhecimento alquímico desde sua origem até o seu declínio não foi em vão, usando as palavras de TRAMER et al. (2007, p. 17, tradução nossa), a "alquimia preparou o terreno em que a química foi construída". São inúmeras as heranças desta deixadas àquela: várias substâncias químicas, compostos e reações e também uma ampla gama de técnicas experimentais que permaneceram inalteradas até a introdução da Química do século XX.

Concordamos com Alfonso-Goldfarb (2001), ao dizer que a alquimia não era exatamente um estudo da ciência e da matéria, muito menos uma iniciação espiritual, mas sim, uma cosmologia ou uma forma de conhecimento do mundo. O caráter holístico e místico da alquimia irá se romper para dar lugar à interpretação quantitativa e mecanística do mundo e da matéria. A cosmologia do saber alquímico, apesar das falhas, interrogações e problemas peculiares a qualquer forma de conhecimento, teria se mantido viva e atuante, enquanto as dúvidas e anseios em relação à natureza fossem coerentes com as soluções que seu modelo tinha a oferecer (ALFONSO-GOLDFARB, 2001, p. 238). A ruptura do saber alquímico ocorre pelas contradições que seu contexto causava na nova forma de pensar, o que no futuro culminou no nascimento da Química Moderna.

Por meio da nova historiografia, ou seja, considerando as duas abordagens historiográficas, tanto a internalista como a externalista, é possível estudar a Alquimia com novas compreensões, seu desenvolvimento e seu lugar na sociedade, além disso, os alquimistas não podem ser descartados como fabricantes de processos imaginados, meros empíricos ou fraudes (PRINCIPE, 2011). 
Dessa forma, o ensino de História e Filosofia da Ciência assume um papel relevante na formação dos professores. Conhecer o passado, o contexto no qual determinados conhecimentos foram elaborados, compreender sua evolução e as diversas visões que os explicam, permite ao professor entender o papel da Ciência como um recorte da realidade que se relaciona com outras áreas e atividades humanas. Nesse sentido, o professor poderá criar soluções e proporcionar um ensino mais eficaz e contextualizado. Tanto a História como a Filosofia da ciência podem auxiliar os professores a repensarem sua prática e a considerarem as relações cotidianas como algo importante à aprendizagem do aluno (PENITENTE; CASTRO, 2010).

A História da Química tem uma grande importância dentro da Ciência e é por meio dela que podemos refletir quanto ao progresso que o homem tem feito no decorrer dos séculos, adquirindo experiência, investigando e descobrindo fatos que fizeram com que o modo de vida de seguidas gerações pudessem ser melhorado (CEBULSKI; MATSUMOTO, 2020; VICENTE; PINTO; SILVA, 2020).

\section{Referências}

ALFONSO-GOLDFARB, A. M. O que é história da ciência. São Paulo: Brasiliense, 1994.

ALFONSO-GOLDFARB, A. M. Da alquimia à química. São Paulo: Landy Editora, 2001.

ALFONSO-GOldFARB, A. M.; FERRAZ, M. H. M.; BELTRAN, M. H. R.; PORTO, P. A. Percursos de história da química. São Paulo: Editora Livraria da Física, 2016.

ANUNCIAÇÃO, B. C. P.; NETO, H. S. M.; MORADILLO, E. F. Robert Boyle no contexto da transição para a ciência moderna: elementos para uma análise sócio-histórica. Revista Ideação, v. $1, n$. 29, p. 165-192, 2014.

BADILLO, R. G.; MIRANDA, R. P. Una aproximación a un análisis histórico y social general de la alquimia. Educacion Química, v. 25, n. 2, p. 104-112, 2014.

BELTRAN, M. H. R.; SAITO, F.; TRINDADE, L. S. P. História da ciência: tópicos atuais. São Paulo: Editora Livraria da Física, 2010.

BELTRAN, M. H. R.; SAITO, F.; TRINDADE, L. S. P. História da ciência para formação de professores. São Paulo: Editora Livraria da Física, 2014

BENSAUDE-VINCENT, B.; STENGERS, I. História da Química. Portugal: Instituto Piaget, 1992.

BIGHETTI, R. C. História da Ciência e livro didático: Robert Boyle e o PNLD 2018-2020. 2019. 147f. Dissertação (Mestrado em Educação para a Ciência) - Universidade Estadual Paulista, Faculdade de Ciências, Bauru, SP.

BOYLE, R. The Origin of forms and Qualities (according to the corpuscular philosophy) illustrated by (1) considerations and (2) experiments 1. The Theoretical Part (1666). Tradução de Jonathan Bennett, 2017. Disponível em: < https://www.earlymoderntexts.com/assets/pdfs/boyle1666_2.pdf>. Acesso em: 05 jan. 2020. 
BRIBIESCA, L.; ROBLES, J. En busca de la piedra filosofal: 0 ¿ deberia todo químico moderno saber algo de alquimia? Parte I: La alquimia como sistema de pensamento. Educación Química, v. 16, n. 1, p. 199-207, 2005.

CÁRDENAS, J. L. La investigación científica y el problema de su justificación en la discusión Boyle / Spinoza. Ideas y Valores, v. 54, n. 128, p.1-21, Bogotá, 2005.

CEBULSKI, E. S.; MATSUMOTO, F. M. A História da Química Como Facilitadora da Aprendizagem do Ensino de Química. Universidade Federal do Paraná (UFPR). Disponível em: <http://www.diaadiaeducacao.pr.gov.br/portals/pde/arquivos/2035-8.pdf> Acesso em: 30 set. 2020.

CECON, K. A relação entre filosofia mecânica e os experimentos alquímicos de Robert Boyle. 2010. 160f. Tese (Doutorado em Filosofia) - Instituto de Filosofia e Ciências Humanas, Universidade Estadual de Campinas, SP.

CECON, K. Um exemplo de negação do conceito de elemento na filosofia natural. História da Ciência e Ensino: construindo interfaces, v. 8, n. 1, p. 68-89, 2013.

CHASSOT, A. A ciência através dos tempos. São Paulo: Moderna, 1994.

DEBUS, A. G. O homem e a natureza no renascimento. Portugal: Editora Porto, 2002.

ELIADE, M. Herreros y Alquimistas, trad. castelhana, Madrid: Alianza Ed. (com autorização de Taurus Ed.), 1974.

FARIAS, R. F. Paracelsus, e a alquimia medicinal. São Paulo: Gaia, 2006.

FARIAS, R. F. História da alquimia. Campinas, SP: Editora Átomo, 2010.

FEDERMANN, R. La Alquimia. Editorial Bruguera, S.A, 1972.

FREZZATTI Jr., W. A. Boyle: a introdução do mecanicismo na química. Revista Varia Scientia, v. 5, n. 9, p. 139-156, 2005.

KUHN, Thomas S. A Estrutura das Revoluções Científicas. 5. ed. São Paulo: Perspectiva, 2000.

LIMA, T. A.; SILVA, M. N. Alquimia, Ocultismo, Maçonaria: o ouro e o simbolismo hermético dos cadinhos (séculos XVIII e XIX). Anais do Museu Paulista. São Paulo, n. 1, v. 8/9, p. 9-54, 2003.

MAAR, J. H. História da química. Florianópolis, SC: Conceito Editorial, 2008.

MOREIRA, M. A.; MASSONI, N. T. Subsídios Epistemológicas para o Professor Pesquisador em Ensino de Ciências. Porto Alegre, Brasil, 2016.

PÁEZ, A. M.; GARRITZ, A. Mujeres y química Parte I. De la antigüedad al siglo XVII. Educación Química, v. 24, n. 1, p. 2-7, 2013.

PARDO, J. Q. Aproximación a los orígenes de la química moderna. Educación Química, v. 13, n. 1, p. 45-54, 2002.

PEDUZZI, L. O. Q.; MARTINS, A. F. P.; FERREIRA, J. M. H. Temas de história e filosofia da ciência no ensino. Natal, RN: EDUFRN, 2012. 
PENITENTE, L. A. A.; CASTRO, R. M. A história e filosofia da ciência: contribuições para o ensino de ciências e para a formação de professores. Revista Eletrônica Pesquiseduca, v. 2, n. 4, p.231244, 2010.

PORTO, P. A. Os três princípios e as doenças: a visão de dois filósofos químicos. Química Nova, v. 20, n. 5, p. 569-572, 1997.

PRINCIPE, B. L. M. Alchemy Restored. Focus-Isis, v. 102, n. 2, p. 305-312, 2011.

PRINCIPE, L. M. The Secrets of Alchemy. Science History Institute, Philadelphia, Estados Unidos, 2013. Disponível em: <https://www.sciencehistory.org/distillations/the-secrets-of-alchemy>. Acesso em: 06 jan. 2020.

ROBLES, J.; BRIBIESCA, L. En busca de la piedra filosofal: 0 ¿̇deberia todo químico moderno saber algo de alquimia? Parte II: Historia de la alquimia como búsqueda de conocimiento y práctica. Educación Química, v. 16, n. 2, p. 338-346, 2005.

SANTOS, A. R.; COSTA, E. S. C.; SILVA, E. L. Da medicina de Hipocrátes ao início de Boyle: um olhar da filosofia e história da química. In: Anais do XVI Encontro Nacional de Ensino de Química/X Encontro de Educação Química da Bahia. Salvador, Bahia, 2012.

SILVEIRA, F. P. R. A.; OlIVEIRA, T. R. C.; PINHEIRO, L.; MENDONÇA, C. A.S.; KOCK, A. A contribuição da Epistemologia da Ciência para o ensino e a pesquisa em Ensino de Ciências: de Laudan a Mayr. Disponível em: <http://www.nutes.ufrj.br/abrapec/viiienpec/resumos/R0898-1.pdf>. Acesso em: 20 mai. 2019.

STRATHERN, P. O Sonho de Mendeleiev: a verdadeira história da química. Rio de Janeiro: Jorge Zahar Editor, 2002.

TRAMER, A.; VOLTZ, R.; LAHMANI, F.; SZCZEPINSKA-TRAMER, J. What Is (Was) Alchemy?. Acta Physica Polonica A, v. 112, n. 1, p. 5-18, 2007.

VANIN, J. A. Alquimistas e químicos: o passado, o presente e o futuro. São Paulo: Moderna, 1994.

VICENTE, S. A.; PINTO, J. A. F.; SILVA, A. P. B. História da Ciência, experimentação e vídeos: introdução ao conteúdo de circuitos elétricos. Ensino de Ciências e Tecnologia em Revista. v. 10, n. 2, p. 151-165, 2020.

ZATERKA, L. As teorias da matéria de Francis Bacon e Robert Boyle: forma, textura e atividade. Scientiae Studia, v. 10, n. 4, p. 681-709, 2012.

\section{Agradecimentos}

À CAPES 